\title{
Plant nutrient uptake in recirculation culture of tomato under growth stage based electrical conductivity adjustments
}

\author{
W.A.P. Weerakkody ${ }^{*}$, K. Wakui ${ }^{2}$ and A. Nukaya ${ }^{2}$ \\ ${ }^{I}$ Dept. of Crop Science, Faculty of Agriculture, University of Peradeniya, Peradeniya. \\ ${ }^{2}$ Faculty of Agriculture, Shizuoka University, Ohaya, Shizuoka, Japan.
}

Revised: 26 November 2010 ; Accepted: 17 December 2010

\begin{abstract}
Recirculation (closed) type hydroponics, despite its comparative eco-friendliness and cost-effectiveness, is less popular in greenhouse agriculture due to the need for close monitoring of nutrient availability within the fertigation cycle. As a practicable and low cost measure, the uptake volume based supplementation of plant nutrients at high concentrations was studied in tomato (Solanum lycopersicum L.) plants at different stages of maturity using the nutrient film technique (NFT). The plants of four age groups or maturity stages (MS), 5, 4, 3 and 2 weeks old at transplanting (MS1, MS2, MS3 and MS4, respectively), were grown in a complete hydroponic solution (Enshi), keeping the electrical conductivity (EC) set-point at 1.8 $\mathrm{dS} \mathrm{m}^{-1}$. EC of the stock solution was maintained at $1.6 \mathrm{dS} \mathrm{m}^{-1}$ until the flowering stage and then changed to 1.1, 1.2, 1.6 and $1.7 \mathrm{dS} \mathrm{m}^{-1}$ in treatments MS1 through MS4 respectively. Young leaves were removed in MS1 while old leaves were removed in MS4 during the last two weeks to create substantially different nutrient demands among the MS treatments. The depleted volume of the supply solution was supplemented daily during the 1-2 week recirculation cycles. EC of the supply solution was monitored and the $\mathrm{pH}$ was adjusted to 6.5 daily.
\end{abstract}

EC did not change appreciably with relatively matured stage transplants (MS1 and MS2) at the beginning due to high nutrient and water uptake rates, while in relatively young stages (MS3 and MS4) uptake concentrations (except for sulphur) were low. Under different water uptake rates, as determined by the prevailing evaporative demand, plants in all MS treatments regulated the uptake rates of macro nutrients $\left(\mathrm{me} \mathrm{day}^{-1}\right)$ by adjusting respective uptake concentrations $\left(\mathrm{me} \mathrm{L}^{-1}\right)$. Time of reaching reproductive stage and growth rate were not affected by MS at transplanting or variable EC management. Hence, $\mathrm{N}, \mathrm{P}, \mathrm{K}, \mathrm{S}, \mathrm{Ca}$ and $\mathrm{Mg}$ uptake rates of NFT grown tomato are basically governed by water uptake rate and further regulated by the uptake concentration.

Keywords: Electrical conductivity, nutrient film technique, nutrient uptake, recirculation hydroponics system, water uptake.

\section{INTRODUCTION}

Nutrient requirements of greenhouse vegetable plants vary with the growth stage, crop management and seasonal and daily variations in environmental parameters (Ito, 1999; Jensen, 1999). In Japan and many other countries in the region, greenhouse growers use commercially available nutrient formulae successfully for open (non re-circulation) systems of hydroponics (Nukaya et al., 1995; Ito, 1999). However, their fertigation strategy, which wastes $20-30 \%$ of the nutrient solution through drainage, is inefficient in both nutrient and water use and is less friendly to the environment. Closed systems of hydroponics, where nutrient solution used is collected and re-circulated with corrections for the plant nutrient availability, address the above issues but need close monitoring to minimize unforeseen and sudden unavailabilities or toxicities of some of the essential plant nutrients (Nukaya et al., 1995; Dorais, 2001).

Although sophisticated automatic fertigation systems, which are manoeuvred through specific decision-support software can fulfil this task, their applicability remains low in medium-input level farming scenarios. Eventhough uptake volume based continuous nutrient supplementing systems with semi-automatic control devices are costeffective, for improved risk management, they still need to be equipped with costly nutrient sensors and dispensers etc. (Gieling et al., 2005).

Meanwhile, estimation of the daily replenishment need using indirect measurements of nutrient availability is an optional nutrient management strategy in the nutrient film technique (NFT) and other flowing hydroponics systems (Weerakkody et al., 2007). Changes of electrical

\footnotetext{
*Corresponding author (palithaw@pdn.ac.lk)
} 
conductivity (EC), $\mathrm{pH}$ and water levels of the nutrient solution in response to daily nutrient and water demand by plants is the basis of this approach. For instance, a downward shift in EC is an indication of relatively high overall nutrient uptake, compared to water uptake and vice versa. This is mainly governed by the demand for nutrients (active uptake) and the rate of transpiration (passive uptake) (Schwarz, 1995; Halvin et al., 2005). Increasing $\mathrm{EC}$ within a certain range increases the uptake rate (me plant ${ }^{-1}$ day $\left.^{-1}\right)$ of macro nutrients. According to previous studies the upper limit of $\mathrm{EC}$ for matured stages of tomato vary within 1.6 - $2 \mathrm{dS} \mathrm{m}^{-1}$ (Jang \& Nukaya, 1997; Li et al., 2001). The balance between active and passive components of the uptake rate of a selected mineral ion determines its uptake concentration $\left(\mathrm{me} \mathrm{L}^{-1}\right)$ (Jang, \& Nukaya, 1997; Nukaya \& Jang, 2000). Meanwhile, increasing $\mathrm{pH}$ is an indication of relatively high rate of anion uptake and vice versa. Therefore, adjusting the EC of the supply solution to match with the water and overall nutrient demands for a given plant, growth stage and weather conditions would be an effective and userfriendly approach in nutrient management of recirculation type hydroponics.

In the present study, a recirculation hydroponics system for tomato plants was tested for the possibility of depleted volume based supplementing of plant nutrients by analysing the uptake characteristics of macro nutrients at selected solution EC levels and growth stage based nutrient demands.

\section{METHODS AND MATERIALS}

The experiment was conducted under temperature controlled glass house conditions in the Shizuoka University, Shizuoka, Japan (Longitude; $34^{\circ} 58^{\prime}$ and Latitude; $138^{\circ} 24^{\prime}$ ) during autumn - winter 2006. The average day and night temperatures were $14-23^{\circ} \mathrm{C}$ and $3-14{ }^{\circ} \mathrm{C}$ respectively, while average relative humidity during the day and night were $55 \%$ and $72 \%$ respectively. The mean solar radiation at mid day was $161 \mathrm{Wm}^{-1}$ during the experimental period and the day length gradually reduced from 12 to $10 \mathrm{~h}$ during the cropping season.

Tomato (Solanum lycopersicum L.) cultivar Momothero Sakata Seeds, Yokohama, Japan) was used for the experiment. The seedlings were raised in rock wool cubes with periodical supply of plant nutrients. Transplanting was done 2 - 5 wks after emergence onto $22 \mathrm{~cm}$ wide NFT troughs placed on raised benches. NFT troughs were re-circulated with Enshi solution (Nukaya et al., 1995; Enshi, 2002) for $15 \mathrm{~min}$ periods with $5 \mathrm{~min}$ intervals in $24 \mathrm{~h}$ cycles. Enshi solution contains $\mathrm{NO}_{3}-\mathrm{N}$, $\mathrm{P}, \mathrm{K}, \mathrm{Ca}$ and $\mathrm{Mg}$ at 224 (16), 41 (4), 312 (8), 160 (8), and 49 (4) ppm (me L-1) (Enshi, 2002). Water levels of the supply tanks were maintained by adding fresh nutrient solution from the stock tank continuously. The recirculation process was continued for 1 to $2 \mathrm{wk}$ periods and renewed when the EC of the supply solution deviated from the set levels substantially. A trough containing a single row of 8 plants was used as a treatment plot, which was replicated three times.

The experiment was conducted in two phases using a completely randomized design with slight differences in the EC set-points in the solutions. The treatments in the first phase (Phase-I) were set based on the maturity stage of seedlings at transplanting (MS), while it was combined with the concentration of the nutrient supply (EC) during Phase-II based on the sensitivity of the age of transplants and growth response of matured plants to high solution EC levels (Savvas \& Lenz, 1995; Nakano et al., 2006; Weerakkody et al., 2007). In the last two weeks of Phase-II, foliage management (leaf pruning) practices were applied along with EC treatments. In Phase-I, 1 to 5 wks after transplanting (WAP), four levels of maturity stages (MS) 1 - 4, were transplanted 5, 4, 3 and 2 wks after seeding, respectively. Nursery management of the maturity stage treatment 1 (MS-1) began on rock-wool cubes on the $13^{\text {th }}$ of September, 2006 and transplanted 5 wks later. The nursery management and transplanting of other treatments were done subsequently in such a manner where MS-1, MS-2, MS-3 and MS-4 were 6, 5, 4 and 3 wks old, respectively at 1 WAP at which time the recirculation of the nutrient solution was started with EC and $\mathrm{pH}$ controls. All four treatments were supplied with the same nutrient solution, having an initial EC of $1.8 \mathrm{dS}$ $\mathrm{m}^{-1}$ in the supply tank and $1.6 \mathrm{dS} \mathrm{m}^{-1}$ in the stock tank. The $\mathrm{pH}$ of the supply tank was adjusted to 6.5 daily.

During the second phase (Phase-II) (6-9 WAP), the stock tank EC of MS1 and MS-2 were decreased to 1.1 and $1.2 \mathrm{dS} \mathrm{m}^{-1}$ respectively, while MS-3 and MS-4 were kept at 1.6 and $1.7 \mathrm{dS} \mathrm{m}^{-1}$ respectively. The selection of EC levels was based on the variably diminishing nutrient demands during late and early reproductive phases. Only treatments MS- 1 and MS-4 were maintained during the last 2 wks ( 8 and 9 WAP) with severe removal of younger leaves (upto 3-4 whorls down the shoot apices) in MS-I and removing of older leaves in MS-4 as a measure to create a contrasting nutrient demand by relatively old and young growth between the two treatments.

Regular maintenance activities such as crop supporting with stakes, plant training (by removal of side shoots and leaves) and pollination aids (by shaking) were practiced as described in Nukaya et al. (1997). The volume of water uptake was determined based on the 
changes in water level of the stock tank, and $\mathrm{EC}$ and $\mathrm{pH}$ of the supply solution were determined at $12 \mathrm{~h}$ intervals. Solution samples from the supply tank were analysed for the availability of $\mathrm{NO}_{3}-\mathrm{N}, \mathrm{NH}_{4}-\mathrm{N}, \mathrm{P}, \mathrm{K}, \mathrm{Ca}$ and $\mathrm{Mg}$ weekly (Jang et al., 1997). The difference between the nutrient composition in the used solution (after $1 \mathrm{wk}$ ) and the supply solution at the beginning of the circulation cycle was taken as an estimate of the weekly uptake rate of the particular nutrient for the whole experiment. This figure could be divided by the depleted volume in the stock tank during the week to estimate the uptake concentration. Plant growth and reproductive maturity were determined in terms of Leaf Area Index (LAI), plant height and rate of anthesis. Data were subjected to single factor analysis of variance, and when a significant F-test was obtained, means were separated using Duncan's MRT $(p=0.05)$.

\section{RESULTS}

\section{EC and $\mathrm{pH}$ variations}

EC of the supply solution in all four maturity stage (MS) treatments remained above the set point for two weeks and then declined until the $5^{\text {th }}$ week after transplanting (WAP) (Phase I). However, significantly higher values $(p=0.05)$ were observed in MS-1 and MS-2 during the $5^{\text {th }}$ week (Figure 1). After decreasing the stock solution EC of MS-1 and MS-2 to 1.1 - 1.2 $\mathrm{dS} \mathrm{m}^{-1}$ while keeping comparatively higher levels in MS-3 and MS-4 (1.6 - 1.7 $\left.\mathrm{dS} \mathrm{m} \mathrm{m}^{-1}\right)$ in the $6^{\text {th }}$ and $7^{\text {th }}$ weeks (Phase II), the EC values of all four treatments returned to a midpoint of $1.5 \mathrm{dS}$ $\mathrm{m}^{-1}$ (Figure 1). Hence, for more matured stages, which probably were in the declining phase of nutrient demand, maintenance of EC at a relatively low level was adequate. After leaf pruning in the $8^{\text {th }}$ and $9^{\text {th }}$ WAP, daily deviations of EC in more matured plants (having older leaves) were higher than less matured plants (having younger leaves) (Table 1).

Meanwhile, daily drift of $\mathrm{pH}$ in the supply solution was not significantly different among MS treatments throughout the experiment. Solution $\mathrm{pH}$ drifted from a mildly acidic set point (6.5) to mild alkaline levels (7.4 - 7.8). The lowest $\mathrm{pH}(6.75)$ was found in the $2^{\text {nd }}$ WAP (Figure 2). The overall pH drift during Phase II was slightly higher than that of Phase I (Table1).

\section{Water uptake}

Figure 3 shows that daily water uptake increased rapidly upto the $3^{\text {rd }}$ WAP, reduced during the $4^{\text {th }}$ week and either remained the same rate or increased slightly in subsequent weeks before reducing significantly during the $7^{\text {th }}$ week. The daily water uptake of maturity stages was significantly different $(\mathrm{p}=0.05)$ and the means were in the order of stages MS-1 > MS-2 > MS-3 > MS-4 until each growth stage treatment came to a peak or stable rate of uptake (Figure 3). The mean daily water absorption was approximately $1 \mathrm{~L}$ per plant under favourable EC and high rates of nutrient uptake during Phases 1 and II

Table 1: EC, $\mathrm{pH}$ and rates of water and nutrient uptake by different maturity stages (MS) of tomato at each growth phase

\begin{tabular}{|c|c|c|c|c|c|c|c|c|c|c|}
\hline \multirow{2}{*}{$\begin{array}{l}\text { Phase } \\
\text { / MS }\end{array}$} & \multirow{2}{*}{$\begin{array}{l}\text { EC } \\
\left(\mathrm{dS} \mathrm{m}^{-1}\right)\end{array}$} & \multirow[t]{2}{*}{$\mathrm{pH}$} & \multirow{2}{*}{$\begin{array}{c}\text { Water } \\
\text { uptake }(\mathrm{L} \\
\left.\text { plant }^{-1} \text { day }^{-1}\right)\end{array}$} & \multicolumn{7}{|c|}{ Nutrient uptake (mg plant ${ }^{-1}$ day $^{-1}$ ) } \\
\hline & & & & $\mathrm{NO}_{3}$ & $\mathrm{P}$ & $\mathrm{S}$ & $\mathrm{NH}_{4}$ & $\mathrm{~K}$ & $\mathrm{Ca}$ & $\mathrm{Mg}$ \\
\hline 1 & $2^{\mathrm{a}}$ & 7.2 & $1.06^{\mathrm{a}}$ & $146^{\mathrm{a}}$ & $41^{\mathrm{a}}$ & $23^{\mathrm{a}}$ & $21.3^{\mathrm{a}}$ & $266^{\mathrm{a}}$ & $149^{\mathrm{a}}$ & $32^{\mathrm{a}}$ \\
\hline 2 & $1.9^{\mathrm{a}}$ & 7.3 & $0.88^{\mathrm{b}}$ & $135^{\mathrm{a}}$ & $34^{\mathrm{a}}$ & $17^{\mathrm{ab}}$ & $17.9^{\mathrm{a}}$ & $223^{\mathrm{a}}$ & $131^{\mathrm{a}}$ & $28^{\mathrm{a}}$ \\
\hline 3 & $1.7^{\mathrm{b}}$ & 7.2 & $0.58^{\mathrm{cd}}$ & $106^{\mathrm{b}}$ & $24^{\mathrm{b}}$ & $11^{\mathrm{bc}}$ & $14.6^{\mathrm{b}}$ & $166^{\mathrm{b}}$ & $103^{\mathrm{b}}$ & $21^{\mathrm{ab}}$ \\
\hline 4 & $1.7^{\mathrm{b}}$ & 7.1 & $0.39^{\mathrm{d}}$ & $75^{\mathrm{b}}$ & $16^{\mathrm{b}}$ & $5.8^{\mathrm{c}}$ & $11.0^{\mathrm{b}}$ & $118^{\mathrm{c}}$ & $79^{\mathrm{b}}$ & $15^{\mathrm{b}}$ \\
\hline IIa 1 & $1.7^{\mathrm{x}}$ & 7.4 & $1.17^{\mathrm{x}}$ & $122^{x y}$ & $33^{x}$ & $30^{\mathrm{x}}$ & $15.5^{\mathrm{x}}$ & $233^{x}$ & $107^{y}$ & $22^{y}$ \\
\hline 2 & $1.6^{x}$ & 7.6 & 1.16 & $142^{x}$ & $33^{x}$ & $31^{x}$ & $15.7^{x}$ & $238^{x}$ & $116^{x y}$ & $23^{y}$ \\
\hline 3 & $1.7^{\mathrm{x}}$ & 7.6 & $1.02^{\mathrm{x}}$ & $154^{x}$ & $38^{x}$ & $29^{x}$ & $17.8^{\mathrm{x}}$ & $239^{x}$ & $133^{x}$ & $31^{x}$ \\
\hline 4 & $1.6^{\mathrm{x}}$ & 7.6 & $0.81^{y}$ & $143^{x}$ & $33^{x}$ & $20^{y}$ & $15.6^{x}$ & $218^{y}$ & $118^{x y}$ & $28^{x}$ \\
\hline IIb 1 & $1.5^{\mathrm{y}}$ & 7.0 & $1.1^{\mathrm{x}}$ & $106^{y}$ & $29^{x}$ & $31^{x}$ & $13.8^{x}$ & $211^{\mathrm{y}}$ & $41^{z}$ & $11^{z}$ \\
\hline 4 & $1.9^{\mathrm{x}}$ & 6.8 & $0.9^{x y}$ & $80^{z}$ & $30^{\mathrm{x}}$ & $3.5^{z}$ & $14.9^{x}$ & $235^{x}$ & $21^{z}$ & $8^{z}$ \\
\hline
\end{tabular}

I - Phase I ( 0 - 5 WAP) IIa - Phase I (6 \& 7 WAP) IIb- Phase II ( 8 \& 9 WAP)

In each phase, means with different superscripts are significantly different at $\mathrm{p}=0.05$ 
of the experiment (Table 1). Under favourable weather conditions with fairly high rate of evapotranspiration the water uptake rates of plants having older leaves were significantly higher $(\mathrm{p}=0.1)$ than the plants with younger leaves (Table 1).

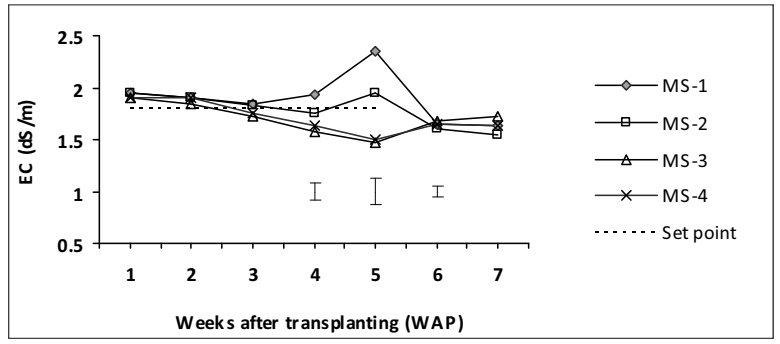

Figure 1: Daily EC drift of the supply solution after transplanting different maturity stages (MS) of tomato (vertical bars represent LSDs at $\mathrm{p}=0.05$ )

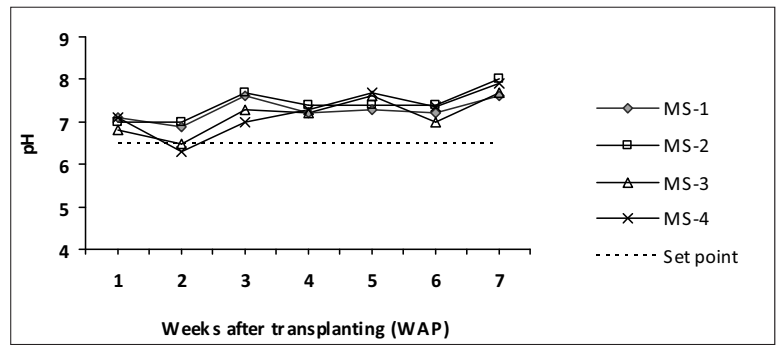

Figure 2: Daily $\mathrm{pH}$ drift of the supply solution after transplanting different maturity stages (MS) of tomato

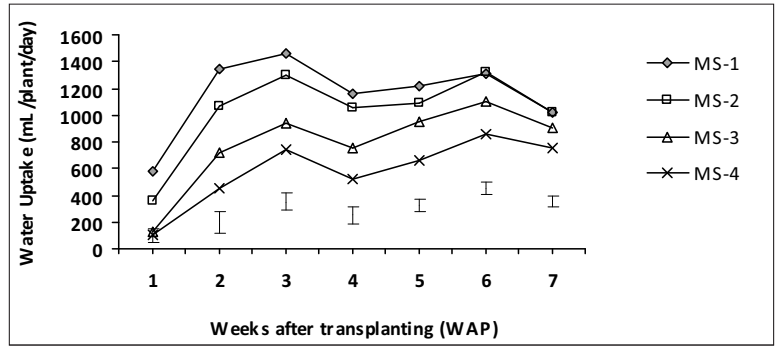

Figure 3: Daily water uptake by different maturity stages (MS) of tomato (vertical bars represent LSDs at $\mathrm{p}=0.05$ )

\section{Nutrient uptake}

Phase I: Figures 4 and 5 illustrate a gradual increase in the daily uptake rates of plant nutrients, N, P, K, S, Ca and $\mathrm{Mg}$ by the plants of maturity stages (MS) 1 and 2 upto 3 WAP and MS-3 and MS-4 upto 5 - 6 WAP. Uptake rate of each nutrient was significantly different $(\mathrm{p}=0.05)$ between MS treatments and was in the order of MS-1 > MS-2 > MS-3 > MS-4 up to 3 WAP, becoming similar to the treatment differences found for the water uptake rate (Figure 3). Hence, rate of macro nutrient uptake during the early post-transplant period was positively correlated with the rate of water uptake $(r=0.72-0.88)$, irrespective of their stage of maturity at transplanting. Hence, water uptake was found to be the driving force of the uptake of many plant nutrients in soilless culture of tomato, similar to some other Solanaceae crops (Savvas \& Lenz, 1995). During Phase I, the variation of uptake concentrations of all macro nutrients except $\mathrm{S}$ with time and treatment differences were the inverse of the respective trends of the uptake rates. In contrast, the uptake concentration of $\mathrm{S}$ increased with time and remained significantly higher in MS-1 and MS-2 than MS-3 and MS-4. Hence, uptake concentrations of most macro nutrients were negatively correlated with the respective nutrient uptake rates $(\mathrm{r}=$ - $0.65-0.78$ ). However, the uptake concentrations of $\mathrm{NO}_{3}-\mathrm{N}, \mathrm{P}, \mathrm{K}$ and $\mathrm{Mg}$ were not statistically significant in the different treatments especially just after transplanting in Phase-I (Figures 4 and 5). Significantly higher uptake concentrations in MS-3 and MS-4 contributed to maintain the uptake rate of each plant nutrient in the $4^{\text {th }}$ week as a compensation for the drastically reduced water uptake rates. The uptake rates of $\mathrm{P}, \mathrm{S}, \mathrm{NH}_{4}-\mathrm{N}$ and $\mathrm{Ca}$ in all MS treatments showed a further reduction during the $5^{\text {th }}$ WAP, due to low uptake concentrations, regardless of slight recovery in the water uptake rates.

Phase II: After changing the stock solution EC at the end of the $5^{\text {th }}$ WAP, the uptake rates of nutrients in all four treatments rapidly increased at comparable rates. Therefore, the resultant changes that took place in the supply solution concentrations for relatively matured and less matured plants at the reproductive stages (6 and 7 WAP) were in favour of macro nutrient uptake. Under relatively low water uptake rates in the $6^{\text {th }}$ week, the plants in MS-3 and MS-4 have been able to maintain a higher uptake rate for most of the plant nutrients by increasing their uptake concentrations (Figures 4 \& 5). During the $7^{\text {th }}$ week a substantial reduction in volume (water) as well as concentration of the nutrient uptake have caused the reduction of uptake of all the macro nutrients significantly, except for $\mathrm{NO}_{3}-\mathrm{N}$ and $\mathrm{S}$ (Figures $4 \& 5$ ). 


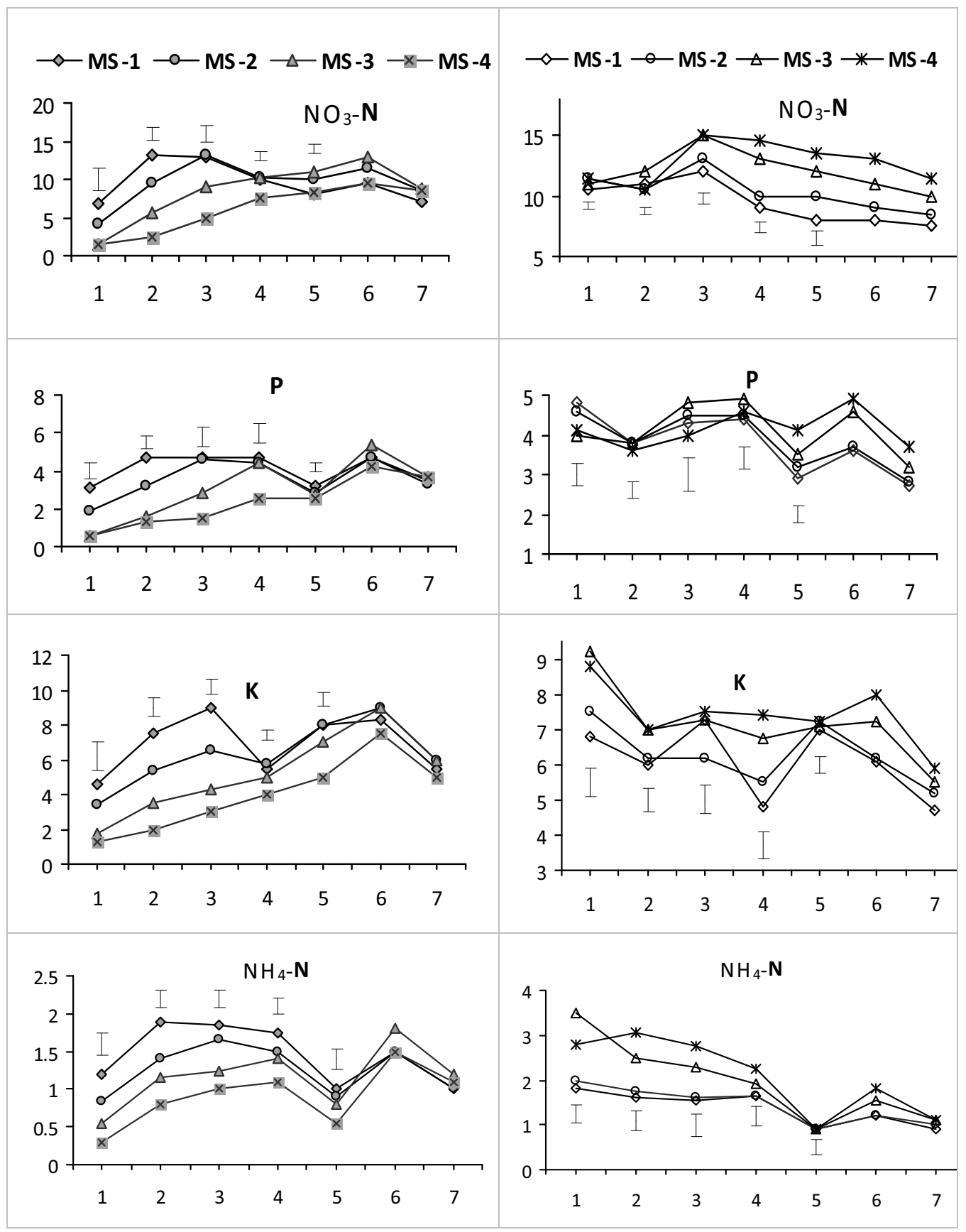

Figure 4: Uptake rate (left; in me plant ${ }^{-1}$ day $^{-1}$ ) and uptake concentration (right; in me $\mathrm{L}^{-1}$ ) of nitrate-N, ammonium-N, phosphorus and potassium (vertical bars represent the LSD at $\mathrm{p}=0.05$ )

Meanwhile the uptake rates of specific macro nutrients were different between two treatments after leaf pruning where $\mathrm{N}$ and $\mathrm{S}$ uptake rates were higher in MS-1 (having older leaves) while $\mathrm{K}$ uptake rate was higher in MS-4 (having younger leaves) (Table 1).

\section{Plant growth and maturity}

Stem elongation and leaf development confirmed maturity stage (MS) specific differences in Phase I (data not shown). There was no evidence of sub-normal 


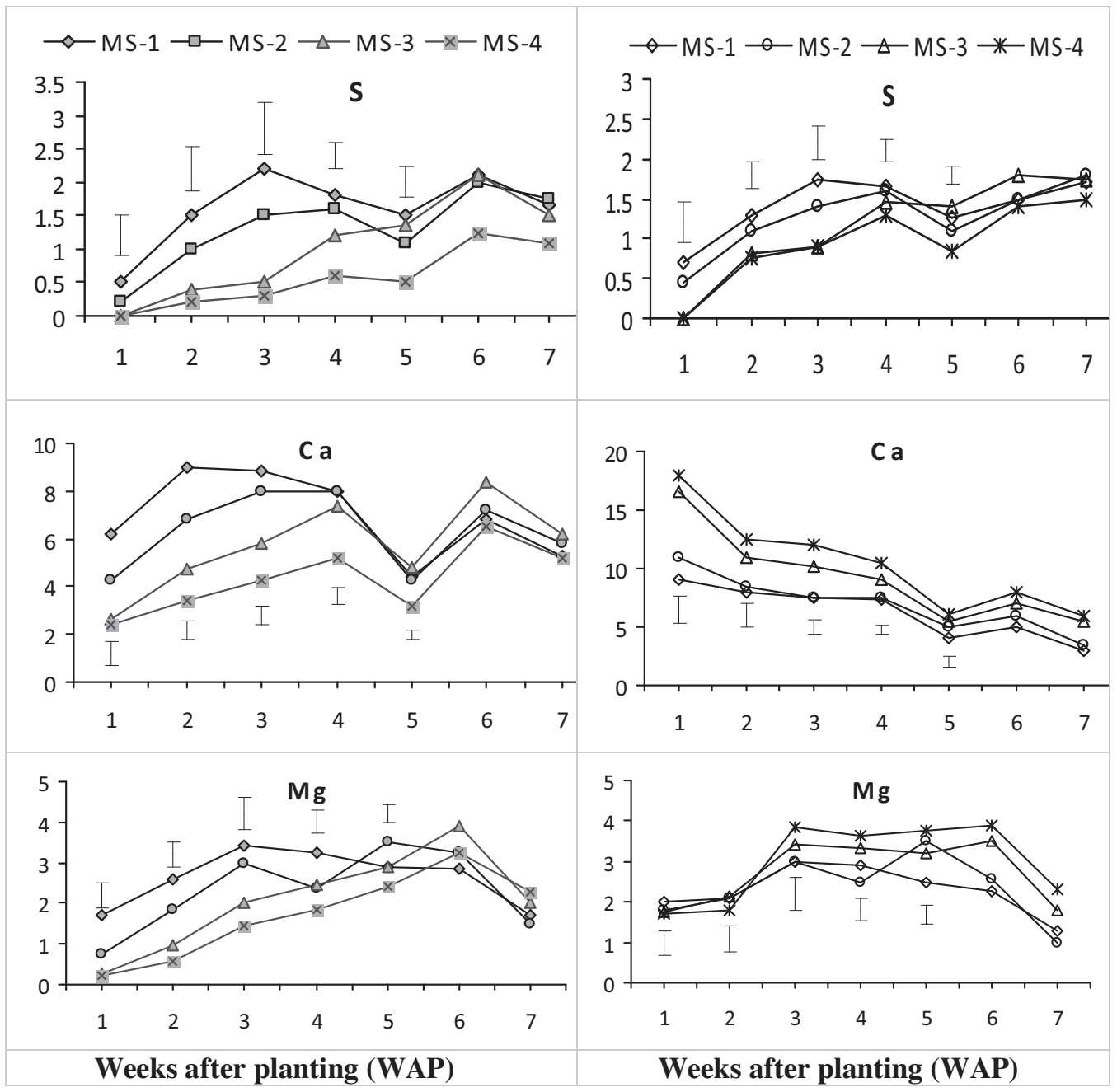

Figure 5: Uptake rate (left; in me plant ${ }^{-1}$ day $^{-1}$ ) and uptake concentration (right; in me $\mathrm{L}^{-1}$ ) of sulphur, calcium and magnesium (vertical bars represent the LSD at $\mathrm{p}=0.05$ )

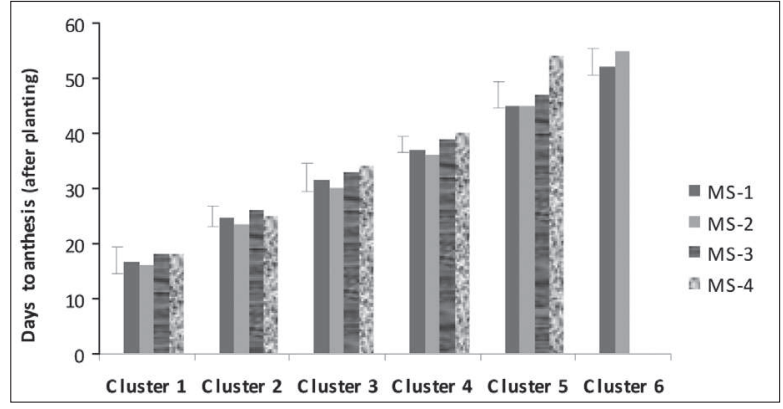

Figure 6: Rate of anthesis of tomato when transplanted at different maturity stages (MS) (Vertical bars represent LSDs at $\mathrm{p}=0.05)$ growth, symptoms of nutrient deficiency or toxicity in any treatment.

There was no difference among treatments in terms of rate of anthesis upto 1-3 clusters. However the $4^{\text {th }}$ cluster of the MS-3 and MS-4 took 3 more days, compared to MS-1 and MS-2. This delay could be due to an amplified scale in subsequent flower clusters (Figure 6).

\section{DISCUSSION}

Direct and indirect measures, taken to improve plant nutrient uptake by tomato plants can be usefully interpreted to improve the knowledge on appropriate EC 
management in recirculation type NFT systems under variable nutritional needs.

Deviation of EC in the supply solution basically reflects the balance between overall nutrient : water uptake rates (Mengal \& Kirkby, 1987). Elevation of EC of the supply solution from a initial set point of $1.8 \mathrm{dS}$ $\mathrm{m}^{-1}$ during the first two weeks after transplanting (1-2 WAP) while the depleted volume (due to plant uptake) is continuously supplemented with a slightly diluted stock solution (EC of $1.6 \mathrm{dS} \mathrm{m}^{-1}$ ) simply indicates more water uptake or a negative balance in nutrient : water uptake rates. Therefore the uptake concentration of most macro nutrients (me $\mathrm{L}^{-1}$ ) must be lower during this period. Only the uptake concentrations of $\mathrm{NO}_{3}-\mathrm{N}, \mathrm{S}$ and $\mathrm{Mg}$ were found to be in the lower extreme. Hence, collective rate of uptake of $\mathrm{NO}_{3}-\mathrm{N}, \mathrm{S}$ and $\mathrm{Mg}$ appeared to be dominating in the overall uptake of macro elements. Furthermore, the "active absorption" of these ions must be fairly low during the initial growth period of tomato.

Meanwhile, medium or higher uptake concentrations of $\mathrm{NH}_{4}-\mathrm{N}, \mathrm{K}$ and $\mathrm{Ca}$ maintained by less matured plants (MS-3 and 4), compared to MS-1 and MS-2 during this period (while maintaining an EC level of $1.8 \mathrm{dS} \mathrm{m}^{-1}$ ), agree with the findings of Nukaya \& Jang (2000) on the ability of young plants to maintain a high uptake concentration (through active absorption) in experiments with other greenhouse crops.

Further reduction of EC in MS-3 and MS-4 during the $3^{\text {rd }}$ and $4^{\text {th }}$ WAP appeared to be an effect of continuous increase in the uptake rates compared to MS-1 and MS-2. Increase and decrease of the uptake concentrations of macro nutrients in matured (MS-1 and 2) and less matured (MS-3 and 4) plants during the $3^{\text {rd }}$ week have contributed appropriately to keep the daily uptake rates in the ascending phase. In the $4^{\text {th }}$ week, less matured stages demonstrated the capability of counteracting the negative influence of reduced water uptake on the nutrient uptake rates by further increasing or stabilizing the uptake concentrations, particularly of anions. Relatively high tendency of anions for active absorption (through negatively charged membranes) and enhanced passive absorption by young plants due to higher permeability of membranes could have collectively favoured this situation (Halvin et al., 2005).

Meanwhile, deviations of $\mathrm{pH}$ from a set point gives a rough idea on the uptake balance of cations: anions from the substrate (Siber, 2002, Unpublished data). Upward drift of $\mathrm{pH}$ or increasing alkalinity in the $3^{\text {rd }}$ week, testifying for a negative balance (more anion uptake) matches with the results on the uptake rates of
$\mathrm{NO}_{3}{ }^{-2}, \mathrm{PO}_{4}^{-3}$ and $\mathrm{SO}_{4}^{-2}$ in the $3^{\text {rd }}$ week. Other than this, $\mathrm{pH}$ drift from a set point of 6.5 (despite daily adjustments) to a mean of 7.6 might be a cause of partial unavailability of micro nutrients (Nakano et al., 2006).

Significant reduction in the uptake rates of $\mathrm{NO}_{3}-\mathrm{N}$ $\mathrm{P}, \mathrm{S}, \mathrm{NH}_{4}-\mathrm{N}$ and $\mathrm{Ca}$ in MS-1 and MS-2 in the $5^{\text {th }}$ week despite fairly high rate of water uptake can be explained as the continuation of the general decline in the crop demand for certain plant nutrients along with maturity. Resultant accumulation of excess nutrients in the MS-1 and MS-2 during the $4^{\text {th }}$ and $5^{\text {th }}$ WAP could be the main reason for sudden elevation of EC in the supply solution in the $5^{\text {th }}$ week. Similarly, further reduction of EC in the supply solutions of MS-3 and MS-4 testifies for a positive balance in the nutrient $=$ water uptake rates, as a result of overall high uptake concentrations of some nutrients. Accordingly, the collective uptake concentrations of $\mathrm{NO}_{3}-\mathrm{N}, \mathrm{S}, \mathrm{K}$ and $\mathrm{Mg}$ must be more effective over the same of $\mathrm{P}, \mathrm{NH}_{4}-\mathrm{N}$ and $\mathrm{Ca}$ at this stage.

Although slight reduction in uptake rates can be expected under low nutrient pressure when EC turns low in MS-3 and MS-4, there was no overall reduction in nutrient uptake rate. This is supported by some of the earlier work on the high capacity of $\mathrm{NO}_{3}-\mathrm{N}$ and $\mathrm{K}$ to be absorbed under low nutrient pressure (Nukaya et al., 1995).

Jang \& Nukaya (1997) have reported the low sensitivity of plant nutrient uptake to variable EC levels during the reproductive phase in experiments with musk melon in rock wool culture. Accordingly, in the $6^{\text {th }}$ week after planting when water uptake was fairly high and the active component of the uptake is also high (reflected by the uptake concentration), rates of uptake of all nutrients have gone up, regardless of the variable stock solution EC in the MS treatments. Meanwhile, reduction of the passive component with the reduced water uptake must be the main reason for slight reduction in uptake rates in 7 WAP.

Alongside the facts discussed in Phase I, more water uptake by MS-1 during 8 and 9 weeks after planting might be a result of relatively low EC in the supply solution. Greater capacity for transpiration due to higher leaf area of the older leaves must be another significant influence. Higher rate of water uptake might have helped $\mathrm{NO}_{3}-\mathrm{N}, \mathrm{Ca}$ and $\mathrm{S}$ to be absorbed passively by contributing much for their overall uptake rates in MS-1. Meanwhile, favourability of a positive concentration gradient for active uptake of $\mathrm{K}$ (Halvin et al., 2005) justifies high $\mathrm{K}$ uptake in MS-4 (under high EC). 
The peak per plant water uptake of $0.6-1.4 \mathrm{~L} \mathrm{day}^{-1}$ falls within the range of the crop water requirement of hydroponic tomatoes under the mean evapo-transpiration rates in typical autumn weather conditions (Schwarz, 1995; Enshi, 2002). Under adequate water uptake rates, daily uptake rates of macro nutrients have reached the mean nutrient demand for hydroponic tomatoes. In comparison with rates of $\mathrm{N}\left(50-55 \mathrm{me} \mathrm{plant}^{-1} \mathrm{wk}^{-1}\right)$ and $\mathrm{P}$ (15 -20 me plant $\left.{ }^{-1} \mathrm{wk}^{-1}\right)$ uptake by tomato in rockwool culture (Terabayashi et al., 2004) and the uptake rates of all macro nutrients in coco-peat culture (Rincon et al., 2005) MS treatments attained the mean plant nutrient demand within the first three weeks, except for $\mathrm{K}$ and S. Less matured transplants (MS-3 and 4) were a little late to attain the mean $\mathrm{K}$ and $\mathrm{S}$ demands (5 - $6 \mathrm{WAP}$ ). Hence, the high EC set point $\left(1.8 \mathrm{dS} \mathrm{m}^{-1}\right)$ together with high stock solution EC during early and late vegetative growth have adequately fulfilled the water and plant macro nutrient demands for tomatoes in recirculation culture, agreeing with some of the early work done under variable conditions for tomato and musk melon, recommending high $\mathrm{EC}$ (upto $2.0 \mathrm{dS} \mathrm{m}^{-1}$ ) in the growing medium, especially for the younger growth stages (Nukaya et al., 2000; Dorais et al., 2001). However, relatively higher EC drift in MS-3 and MS-4 (compared to MS-1 and MS-2) together with their comparatively low peaks in the nutrient uptake rates, the stock solution EC as well as EC set point might need minor adjustments for less matured transplants.

The patterns of treatment differences and timely variations in water and nutrient uptake rates during Phase I match with the measurements obtained on vegetative growth parameters, plant height and LAI (Wakui, 2003) under the same experimental set-up, signifying the consequences of plant water and nutrient uptake rates on the plant growth rate. However, advances in uptake rates or resultant vegetative growth have not significantly affected the flowering rate, or the reproductive development in earlier formed clusters.

Overall results show that uptake of $\mathrm{N}, \mathrm{P}, \mathrm{K}, \mathrm{S}$, $\mathrm{Ca}$ and $\mathrm{Mg}$ in recirculation hydroponics of tomato is basically governed by water uptake rate. When the water uptake rate is moving towards higher or lower extremes, the uptake concentrations of macro elements are adjusted to match with the plant nutrient demand. The set levels of $\mathrm{EC}$ and $\mathrm{pH}$ in the nutrient (supply) solutions were appropriate to maintain a sufficient rate of plant nutrient uptake during most stages of plant growth under variable weather conditions. Therefore, setting supply solution $\mathrm{EC}$ at $1.8 \mathrm{dS} \mathrm{m}^{-1}$ and $\mathrm{pH}$ at 6.5 and maintaining them in a close range with uptake volume based continuous refilling, and with weekly renewals, can be considered as a basic management guideline for NFT of tomato in recirculation culture especially for late vegetative growth and flowering. Gradual reduction of the stock solution $\mathrm{EC}$ afterwards, down to $1.2 \mathrm{dS} \mathrm{m}^{-1}$ (during fruit growth) would also be possible, subject to sufficient water uptake rates. However, fine-tuning of EC set points would be necessary for further improvements of water and nutrient uptake rates during early vegetative and late fruit growth stages.

\section{Acknowledgement}

Authors wish to thank the Association for International Education in Japan (AIEJ) for research funding.

\section{References}

1. Dorais M., Papadopoulos A.P. \& Gosselin A. (2001). Influence of electric conductivity management on greenhouse tomato yield and fruit quality. Agronomie 21(4): 367-383.

2. Enshi (2002). Yoeki Saibai no Shin Manuelu, pp. 4. Japanese Institute for Horticultural Associations, Tokyo, Japan.

3. Gieling T.H., Corver F.J.M., Janssen H.J.J., Straten G., Van Ooteghem R.J.C. \& van Dijkl G.J. (2005). The control of the recirculation drain solution in closed-loop hydroponic systems. Informatore Fitopatologico 55(12): 8-12.

4. Halvin J.L., Beaton J.D. \& Tisdale S.L. (2005). Soil Fertility and Fertilizers: An Introduction to Nutrient Management, pp. 497. Pearson, New Jersey, USA.

5. Ito T. (1999). The greenhouse and hydroponics industries in Japan. Acta Horticulturae 481: 761-764.

6. Jang H.G. \& Nukaya A. (1997). Relationship between concentration of nutrient solution and uptake of nutrients in musk melon grown in rockwool. Journal of the Japanese Society of Horticultural Science 66(2): 307-312.

7. Jensen M.H. (1999). Hydroponics worldwide. Acta Horticulturae 481: 719-729.

8. Li Y.L., Stanghellini C. \& Challa H. (2001). Effect of electrical conductivity and transpiration on production of greenhouse tomato (Solanum lycopersicum L. esculentum L.). Scientia Horticulturae 88(1): 11-29.

9. Mengal K. \& Kirkby E.A. (1987). Principles of Plant Nutrition, pp. 849. International Potash Institute, Bern, Switzerland.

10. Nakano Y., Watanabe S., Kawashima H. \& Takaichi M. (2006). The effect of daily nutrient applications on yield, fruit quality, and nutrient uptake of hydroponically cultivated tomato. Journal of the Japanese Society of Horticultural Science 75(5): 421-429.

11. Nukaya A. \& Jang H.G. (2000). Effect of composition and concentration of nutrient solution on the uptake of mineral elements by musk melon grown in rockwool during fall. Journal of the Japanese Society of Horticultural Science 69(5): 655-657. 
12. Nukaya A., Jang H., Ui N., Goto K. \& Ohkawa K. (1995). Changes of mineral concentrations in plant sap during the growth period of musk melons grown in rock-wool. Acta Horticulturae 396: 167-172.

13. Nukaya A., Jang H. \& Goto K. (1997). Effect of NH4-N levels and $\mathrm{K}$ : Ca ratio in the nutrient solution on incidence of BER and Gold speck on tomato fruits grown in rock wool. In: Plant Nutrition for Sustainable Food Production of Environment (ed. T. Ando), pp. 969-970. Kluwer Academic Publishers, Japan.

14. Rincon L., Perez A. \& Pellicer C. (2005). Yield, water use and nutrient uptake of coconut coir dust. Acta Horticulturae 697:73-79.

15. Savvas D. \& Lenz F. (1995). Nutrient uptake by Capsicum and egg plants in soilless culture. Gartenbauwissenschaft 60(1): 29-33.

16. Schwarz M. (1995). Soilless Culture Management:
Advanced Series in Agricultural Science, pp. 197. Springer Publishers, Germany.

17. Terabayashi S., Muramatsu I., Tokutani S., Ando M., Kitagawa E., Shigemori T., Date S. \& Fujime Y. (2004). Relationship between the weekly nutrient uptake rate during fruiting stages and fruit weight of tomato (Solanum lycopersicum L. esculentum Mill.) grown hydroponically. Journal of the Japanese Society of Horticultural Science 73(4): 324-329.

18. Wakui T. (2003). Effect of variable EC on the plant growth and nutrition of NFT grown tomato. BSc dissertation, Shizuoka University, Shizuoka, Japan.

19. Weerakkody W.A.P., Mayakaduwa M.A.P. \& Weerapperuma K.N. (2007). Effect of supply volume and weather based EC adjustments on the growth and yield of greenhouse tomato and bell pepper. Acta Horticulturae 742:105-111. 